\title{
Association between Aortic Stiffness and Cerebral Pulsatility is Modestly Influenced by Augmentation Index
}

\author{
James Pearson ${ }^{1,2}$, Laura J. Watkeys ${ }^{1}$, James M. Coulson ${ }^{3}$, Zachary J. Schlader ${ }^{4,5}$, Craig G. Crandall ${ }^{4}$, \\ John R. Cockcroft ${ }^{1}$, Carmel M. McEniery ${ }^{6}$, Barry J. McDonnell ${ }^{1, *}$ \\ ${ }^{1}$ Cardiff School of Health Sciences, Cardiff Metropolitan University, Cardiff, UK \\ ${ }^{2}$ Department of Human Physiology and Nutrition, University of Colorado at Colorado Springs, USA \\ ${ }^{3}$ School of Medicine, Cardiff University, Cardiff, UK \\ ${ }^{4}$ Institute for Exercise and Environmental Medicine, Texas Health Presbyterian Hospital Dallas and University of Texas Southwestern Medical Center, Texas, USA \\ ${ }^{5}$ Department of Kinesiology, School of Public Health - Bloomington, Indiana University, Indiana, USA \\ ${ }^{6}$ Experimental Medicine and Immunotherapeutics Division, Department of Medicine, University of Cambridge, Cambridge, UK
}

\section{ARTICLE INFO}

\section{Article History}

Received 01 December 2019

Accepted 01 December 2019

\section{Keywords}

Central pulse pressure cerebral pulsatility augmentation index glyceryl trinitrate $(\mathrm{GTN})$

\begin{abstract}
Central Pulse Pressure (CPP) and Aortic Pulse Wave Velocity (aPWV) share a positive relationship with cerebral pulsatility and are associated with cerebrovascular disorders including stroke. Our aim was to examine the influence of Augmentation Index (AIx) upon this relationship, first by using a cross sectional design across a wide range of CPP and aPWV in healthy individuals and second, following administration of Glyceryl Trinitrate (GTN) to acutely change AIx. We measured CPP, aPWV, AIx and Middle Cerebral Artery Pulsatility Index (MCAPI) in 99 healthy individuals (54 females). In all individuals, after accounting for the effect of age and gender, MCAPI shared an independent inverse relationship with $\operatorname{AIx}\left(\beta=-0.515, R^{2}=0.109 ; p=0.001\right)$, and a positive relationship with CPP $\left(\beta=0.570, R^{2}=0.093 ; p=0.003\right)$ but not aPWV ( $\left.p>0.05\right)$. GTN was administered to 25 of these participants ( 14 females). Following GTN, AIx75 decreased in all participants relative to baseline (12 \pm 19 to $5 \pm 16 \%$; $p=$ $0.0001)$. In the $20 \mathrm{~min}$ following GTN administration, CPP shared a positive relationship with MCAPI $\left(\beta=0.305, R^{2}=0.042 ; p=\right.$ 0.002 ) while AIx, adjusted for heart rate (AIx75), shared an inverse relationship with MCAPI $\left(\beta=-0.320, R^{2}=0.019 ; p=0.031\right)$. These findings indicate that the positive relationship between CPP and MCAPI may be somewhat modified by AIx. This suggests that an increased AIx may weakly attenuate increases in MCAPI that are associated with aortic stiffening in a healthy population at rest, but also following acute reductions in AIx75 after administration of GTN.
\end{abstract}

(C) 2019 Association for Research into Arterial Structure and Physiology. Publishing services by Atlantis Press International B.V. This is an open access article distributed under the CC BY-NC 4.0 license (http://creativecommons.org/licenses/by-nc/4.0/).

\section{INTRODUCTION}

Aortic stiffness, as measured by Aortic Pulse Wave Velocity (aPWV) and Central Pulse Pressure (CPP), increase with healthy aging [1,2] and independently predict cardiovascular mortality, including stroke [3-5]. Large artery stiffness is associated with increased cerebral blood flow pulsatility [6-10] which likely increases the mechanical insult delivered into the cerebral microvasculature [11] and may help to explain the increased frequency of white matter lesions observed in individuals with increased large artery stiffness [12,13]. In line with this hypothesis, individuals with increased cerebral blood flow pulsatility display increased frequency and volume of white matter hyperintensities [14,15] which are associated with incidence of stroke and other cerebrovascular disorders [6,16-19].

As the forward-travelling pressure wave propagates throughout the arterial tree it encounters bifurcations and sites of impedance mismatch that result in a proportion of this pressure wave being

"Corresponding author.Email: bmcdonnell@cardiffmet.ac.uk

Peer review under responsibility of the Association for Research into Arterial Structure and Physiology

Data availability statement: The data that support the findings of this study are available from the corresponding author (BMD), upon reasonable request. reflected back to the aorta. This phenomenon is termed pulse wave reflection [20]. Augmentation Index (AIx) can be used as an index of both the reflected pressure waves [21] and myocardial shortening velocity [22]. A greater AIx increases the risk of cardiovascular events, including stroke [23], target organ damage [19,24] and white matter hyperintensity volume $[25,26]$. In line with this, increased [25] and early wave reflections from the lower body [27] accompany a greater cerebral pulsatility in aged individuals, suggesting that increased AIx may be associated with an increased cerebral blood flow pulsatility and cerebrovascular damage. However, an increased AIx has also been hypothesised to dampen the transmission of highly pulsatile forces travelling from the aorta into the end organ particularly those with a low resistance to flow (e.g. the brain and kidney) $[6,19,28]$.

Therefore, the aim of this study was to further examine the influence of AIx upon cerebral pulsatility in the Middle Cerebral Artery Pulsatility Index (MCAPI) across a wide range of CPP and aPWV values, first, in a cross sectional study design and, second, following acute reductions in AIx with administration of the nitrovasodilator, Glyceryl Trinitrate (GTN) [29,30]. We hypothesised that AIx modifies the relation between markers of aortic stiffening and cerebral pulsatility. 


\section{MATERIALS AND METHODS}

\subsection{Study Population}

Ninety nine individuals (54 females, $45 \pm 16$ years, $75 \pm 15 \mathrm{~kg}$ and $170 \pm 9 \mathrm{~cm}$, Table 1), who were free from current or previous use of anti-hypertensive and/or cardiovascular acting medications and had no diagnosis of cardiovascular disease were recruited and assessed as part of this study. The study protocol information and consent were approved by the Cardiff Metropolitan University ethics committee and the Institutional Review Boards at the University of Texas Southwestern Medical Center at Dallas and Texas Health Presbyterian Hospital Dallas.

\subsection{Protocols}

Height and weight were measured following the completion of a medical history questionnaire where medications were noted. Peripheral (brachial) blood pressure, central (aortic) pulse pressure, aPWV, AIx and MCA blood flow velocity (MCAv) were obtained following at least $15 \mathrm{~min}$ of supine rest.

A subset of 25 individuals ( 14 females, $53 \pm 17$ years, $74 \pm 11 \mathrm{~kg}$ and $169 \pm 10 \mathrm{~cm}$ ) were enrolled in the interventional arm of the study, wherein each individual was given one dose of GTN (400-500 $\mu \mathrm{g})$ while supine. A GTN tablet was positioned sublingually for $3 \mathrm{~min}$ after which time any remaining part of the tablet was discarded. Blood pressure (peripheral and central), AIx and MCAPI were measured simultaneously at baseline and at 1, 3, 5, 10, 15, and 20 min post GTN administration.

\subsection{Hemodynamic Measurements}

\subsubsection{Blood pressure}

Brachial blood pressure was measured whilst supine using a validated semi-automated oscillometric device [31] (HEM-705CP, Omron Corporation and Tango, Suntech Medical Instruments, Raleigh, NC,
USA). At baseline, blood pressure was measured in duplicate, or triplicate if two consecutive readings varied appreciably.

\subsubsection{Central pulse pressure and augmentation index}

Applanation tonometry of the radial artery was used to assess CPP and AIx (SphygmoCor, AtCor Medical, Sydney, Australia). Central (aortic) pressure waves were generated from the radial artery pressure waves using a validated generalized transfer function as previously described [32]. Using the integral software, CPP was calculated as the difference between the aortic systolic and diastolic pressures, while Central Augmentation Pressure (cAP) was calculated as the difference between the second and first aortic systolic pressure peaks (P2 and P1). Pulse wave analysis of the aortic pressure waveform was also used to measure AIx (cAP expressed as a percentage of the aortic pulse pressure). Heart Rate (HR) was determined from the aortic waveform and expressed as beats per minute. Mean Arterial Pressure (MAP) was obtained by integration of the aortic waveform following the measurement and input of brachial systolic and diastolic blood pressures.

\subsubsection{Aortic pulse wave velocity}

Briefly, aPWV was measured using applanation tonometry (SphygmoCor, AtCor Medical, Sydney, Australia) by sequentially recording electrocardiography gated carotid and femoral artery pressure waveforms, as previously described in detail [33]. Path length for the determination of aPWV was measured as the surface distance between the suprasternal notch and the femoral artery measurement site minus the distance between the suprasternal notch and carotid artery measurement site, using a tape measure.

\subsubsection{Cerebral blood flow pulsatility}

Cerebral artery blood flow pulsatility (MCAPI) was measured from the left MCA flow velocity profile (MCAv) using $2 \mathrm{MHz}$ pulsed

Table 1 Descriptive and hemodynamic data of all participants and those administered with GTN

\begin{tabular}{|c|c|c|c|c|}
\hline Parameter & $\begin{array}{l}\text { All participants } \\
\qquad(n=99)\end{array}$ & Range & $\begin{array}{l}\text { GTN study participants } \\
\qquad(n=25)\end{array}$ & Range \\
\hline Age (years) & $45 \pm 16$ & $22-83$ & $53 \pm 17$ & $22-77$ \\
\hline Height (m) & $170 \pm 9$ & $150-190$ & $169 \pm 10$ & $151-185$ \\
\hline Weight (kg) & $75.0 \pm 15.1$ & $48-134$ & $74.0 \pm 10.5$ & $54-112$ \\
\hline BMI $\left(\mathrm{kg} / \mathrm{m}^{2}\right)$ & $25.9 \pm 4.6$ & $18.8-43.8$ & $25.9 \pm 3.4$ & $21.6-37.0$ \\
\hline Males/Females & $45 / 54$ & & $11 / 14$ & \\
\hline MAP (mmHg) & $95 \pm 11$ & $70-128$ & $92 \pm 12$ & $71-114$ \\
\hline Central pulse pressure (mmHg) & $37 \pm 10$ & $21-71$ & $38 \pm 10$ & $21-58$ \\
\hline Heart rate (bpm) & $58 \pm 9$ & $41-77$ & $59 \pm 9$ & $42-72$ \\
\hline Augmentation index (AIx, \%) & $22 \pm 16$ & $-19.5-49$ & $20 \pm 18$ & $-13-49$ \\
\hline Augmentation index 75 (AIx@75, \%) & $14 \pm 16$ & $-28-40$ & $18 \pm 17$ & $-20-40$ \\
\hline Aortic Pulse Wave Velocity (aPWV, m/s) & $7.2 \pm 1.8$ & $4.7-15.3$ & $7.1 \pm 1.5$ & $4.65-9.65$ \\
\hline $\operatorname{MCAv}(\mathrm{cm} / \mathrm{s})$ & $66.9 \pm 12.0$ & 41-99 & $65 \pm 11$ & $46-88$ \\
\hline MCAPI (\%) & $75.0 \pm 11.5$ & $52-113$ & $77.0 \pm 12.2$ & $59-107$ \\
\hline
\end{tabular}

Data are mean \pm SD. BMI, body mass index; MAP, mean arterial blood pressure; MCAv, middle cerebral artery blood flow velocity; MCAPI, middle cerebral artery pulsatility index. 
Doppler ultrasound (Multiflow, DWL Elektronische Systeme, Singen, Germany). MCAv waveforms were recorded beat by beat for $30 \mathrm{~s}$ from which time averaged systolic, mean and diastolic cerebral blood flow velocities were calculated. MCAPI was calculated beat by beat using Gosling's pulsatility index [7,34]: MCAPI = (Systolic MCAv - diastolic MCAv)/(mean MCAv) $\times 100$ and averaged over 30 s. Systolic (Systolic MCAv) and diastolic (Diastolic MCAv) cerebral blood flow velocities were expressed as a percentage by rescaling the respective values by the MCAv which was averaged over $30 \mathrm{~s}$ (mean MCAv) [35,36].

\subsection{Statistical Analysis}

Data were analyzed using simple and hierarchical multivariable regression (SPSS v20, IBM, Armonk, NY, USA). Non-normally distributed variables were $\log$ transformed. The associations between cerebral blood flow pulsatility, aPWV, CPP and AIx were initially analyzed, together with other hemodynamic variables, using linear and curvilinear regression analyses. A hierarchical multivariable regression model was used thereafter to investigate the parameters that were independently associated with MCAPI. Traditional known confounders such as age and gender were forced into the model. This was followed by the stepwise entry of the linear and quadratic terms of aPWV, CPP, AIx, heart rate and MAP. GTN administration can change heart rate and therefore AIx values obtained during GTN administration were standardized to $75 \mathrm{bpm}$ (AIx75) [37]. The same hierarchical multivariable regression analyses were used to examine the relationships between the linear and quadratic terms of aPWV, CPP, AIx, heart rate and MAP with MCAPI at baseline and following GTN administration. These variables were entered into the model in a stepwise method after age and gender had been forced into the model. A one-way ANOVA was also used to analyze the influence of GTN upon CPP, AIx75 and MCAPI over time. A main effect of time was followed up with using a paired $t$-test and a Bonferroni correction was applied where appropriate. Statistical significance was set at $p \leq 0.05$. Unless otherwise stated, results are reported as mean $\pm \mathrm{SD}$. Values reported in the tables, text and figures have been $\log$ transformed where necessary.

\section{RESULTS}

\subsection{Cross Sectional Study}

Baseline descriptive characteristics, pressure and hemodynamic data of all 99 individuals and a subset of those who received GTN are reported in Table 1 . Univariate regression analysis indicated that MCAPI shared a relationship with age $\left(R^{2}=0.057, \beta=0.239\right.$; $p=0.018), \operatorname{CPP}\left(R^{2}=0.161, \beta=0.401 ; p=0.0001\right.$, Figure 1$)$ and $\operatorname{aPWV}\left(R^{2}=0.053, \beta=0.230 ; p=0.028\right)$. After accounting for the effects of age and gender, hierarchical multivariable regression analyses indicated that MCAPI shared an inverse relationship with $\operatorname{AIx}\left(R^{2}=0.109, \beta=-0.515 ; p=0.001\right)$ and a positive relationship with CPP $\left(R^{2}=0.093, \beta=0.570 ; p=0.003\right.$, Table 2$)$. None of the other measured variables shared an independent relationship with MCAPI and were therefore excluded from this regression model.

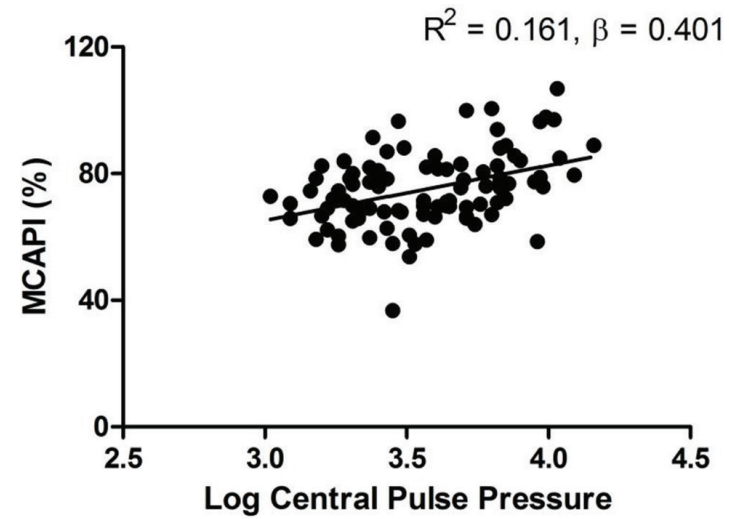

Figure 1 MCAPI shared a positive relationship with CPP across all participants $(p=0.0001)$. Data are from 99 participants.

Table 2 Hierarchical multivariable regression analysis of cerebral blood flow pulsatility (MCAPI) in all individuals

\begin{tabular}{|c|c|c|c|c|}
\hline \multirow[t]{2}{*}{ Model } & \multirow[t]{2}{*}{ Variable } & \multirow{2}{*}{$\begin{array}{c}\begin{array}{c}\text { Overall } \\
\text { model }\end{array} \\
R^{2}(p \text {-value })\end{array}$} & \multirow{2}{*}{$\begin{array}{c}\text { Model } \\
\text { improvement }\end{array}$} & \multirow[t]{2}{*}{$\beta$} \\
\hline & & & & \\
\hline & Log age & & & \\
\hline \multirow[t]{2}{*}{1} & Log age ${ }^{2}$ & & & 0.170 \\
\hline & Gender & $0.042(0.151)$ & & 0.145 \\
\hline 2 & $\begin{array}{l}\text { Log central } \\
\text { pulse pressure }\end{array}$ & $0.135(0.005)$ & $0.093(0.003)$ & 0.570 \\
\hline 3 & $\log \operatorname{AIx}^{2}$ & $0.245(\leq 0.001)$ & $0.109(0.001)$ & -0.515 \\
\hline
\end{tabular}

Only significant predictors of the variance of the dependent variable are shown here with the exception of age, which was forced into the model. Significance was accepted at the $95 \%$ confidence interval. AIx, augmentation index; $\beta$, standardized beta coefficient; $R^{2}$, coefficient of determination.

\subsection{Influence of acute reductions in augmentation index upon cerebral pulsatility}

Baseline descriptive characteristics, pressure and hemodynamic data of the subset of 25 individuals who received GTN are reported in Table 1. Relative to baseline values (18 $\pm 17 \%)$ AIx75 was reduced during the 20-min period following GTN administration (main effect of time: $p<0.001)$ at $3(10 \pm 14 \%, p<0.001), 5(9 \pm 15 \%, p<$ $0.001), 10(11 \pm 17 \%, p<0.001)$ and $15 \min (12 \pm 116 \%, p<0.001)$. $\mathrm{CPP}$ was not different relative to baseline $(36 \pm 9 \mathrm{mmHg})$ at any time point (all $p>0.05)$. Similarly, despite reductions in AIx75 with GTN, MCAPI was unchanged at 3 (74.6 $\pm 13.3 \%), 5$ (75.6 $\pm 11.4 \%)$, $10(76.6 \pm 13.0 \%)$ and $15 \mathrm{~min}(75.9 \pm 13.7 \%)$ relative to baseline (77 $\pm 12.2 \%$, Main effect of time $p=0.63$ ). The time at which the lowest AIx75 occurred in the 20 min following GTN administration was variable between subjects. Therefore, we compared the lowest AIx75 for each subject with MCAPI at that same time point. The lowest AIx75 following GTN was $5 \pm 16 \%$ which was lower relative to baseline $(p<0.001)$. Interestingly, this decrease in AIx75 did not correspond with a change in MCAPI at the same time point relative to baseline ( $77 \pm 12.2 \%$ vs. $75.8 \pm 13.1 \%$; $p=0.56$ ). However, after accounting for the effects of age and gender, hierarchical multivariable regression analyses indicated that MCAPI shared an inverse 
Table 3 Hierarchical multivariable regression analysis of factors explaining the variance in MCAPI following GTN administration

\begin{tabular}{|c|c|c|c|c|}
\hline \multirow{2}{*}{ Model } & \multirow{2}{*}{ Variable } & $\begin{array}{c}\text { Overall } \\
\text { model }\end{array}$ & $\begin{array}{c}\text { Model } \\
\text { improvement }\end{array}$ & \multirow[t]{2}{*}{$\beta$} \\
\hline & & $R^{2}(p$-value $)$ & $\Delta R^{2}(p$-value $)$ & \\
\hline & Age & & & 1.124 \\
\hline \multirow[t]{2}{*}{1} & $\mathrm{Age}^{2}$ & & & -0.594 \\
\hline & Gender & $0.263(\leq 0.001)$ & & -0.296 \\
\hline 2 & $\begin{array}{l}\text { Central pulse } \\
\text { pressure }^{2}\end{array}$ & $0.305(\leq 0.001)$ & $0.042(0.002)$ & 0.330 \\
\hline 3 & AIx75 & $0.324(\leq 0.001)$ & $0.019(0.031)$ & -0.320 \\
\hline 4 & Heart rate & $0.349(\leq 0.001)$ & $0.025(0.013)$ & 0.167 \\
\hline
\end{tabular}

Only significant predictors of the variance of the dependent variable are shown. Significance was accepted at the 95\% confidence interval. AIx@75, augmentation index; $\beta$, standardized beta coefficient; $R^{2}$, coefficient of determination.

relationship with $\operatorname{AIx} 75\left(R^{2}=0.019, \beta=-0.320 ; p=0.031\right)$ and a positive relationship with $\operatorname{CPP}\left(R^{2}=0.042, \beta=0.330 ; p=0.002\right)$ in the $20 \mathrm{~min}$ period following GTN administration (Table 3 ).

\section{DISCUSSION}

The aim of this study was to examine the influence of AIx upon cerebral pulsatility across a wide range of CPP and aPWV values, first, in a cross sectional study design and, second, following acute reductions in AIx with administration of the nitrovasodilator, GTN $[26,27]$. Together, these data indicate that CPP is positively associated and AIx inversely associated with middle cerebral artery blood pulsatility in healthy individuals. These findings have implications for the understanding of the role of CPP and AIx upon cerebral pulsatility.

Both aPWV and CPP share a positive relationship with carotid and cerebral pulsatility in a healthy population [22], leukoaraiosis patients [35] and a mixed group comprising both healthy individuals and those with cardiovascular disease [36,37]. Previous reports examining the relationship between AIx and cerebral pulsatility appear to be conflicting. Aortic AIx shares a positive relationship with cerebral flow AIx [24], while carotid AIx is inversely related with MCAPI [22]. However, the independent influence of AIx upon the relationship between increased CPP and aPWV with cerebral pulsatility index is unknown in a study population comprised exclusively of individuals free from cardiovascular disease, and current and/or prior use of cardiovascular acting medications.

Similar to others [22,25,35-37] our data indicate a positive relationship between CPP and cerebral blood flow pulsatility. However, independent of CPP, these data also indicate a small inverse relationship between AIx and cerebral blood flow pulsatility exists both from cross sectional data and that obtained following acute reduction of AIx75 with GTN. Taken together, these findings suggest that wave reflections may exert a small influence in attenuating increases in cerebral blood flow pulsatility that accompany aortic stiffening and CPP.

Increased cerebral blood flow pulsatility and the accompanying excessive pulsatile shear stress can damage the vascular endothelial layer $[34,35]$ and blood brain barrier leading to the development of white matter lesions [38]. Furthermore, increased cerebral blood flow pulsatility is associated with large artery vascular remodelling, as evidenced by an increased carotid wall thickness and plaque development $[9,13,39]$, which are themselves predictors of cardiovascular risk [40,41]. Vascular remodelling occurs with aging and cardiovascular disease [42] leading to further increases in arterial stiffness and pressure pulsatility causing microcirculatory damage [19], increasing the risk of stroke and the development of white matter lesions $[10,19,36,43-45]$. An increased transmission of pulsatile blood flow into the brain, secondary to large artery stiffening, may help explain the independent association between large artery stiffness and stroke $[3,5,46]$. Furthermore the inverse relationship observed here between AIx75 and MCAPI suggests that increased AIx may attenuate, albeit weakly, the transmission of increased pulsatile flow into the cerebral vasculature, perhaps due to aortic stiffening in a healthy population.

Glyceryl trinitrate and other endothelium-independent vasodilators are often prescribed to individuals with cardiovascular disease, likely in the presence of aortic stiffening. With increasing age, the middle cerebral arteries exhibit impaired myogenic response to increased pulsatility that potentially contributes to distal cerebral microvascular damage [47] and intracerebral haemorrhage [48]. Following GTN administration, AIx75 was lowered while CPP remained unchanged relative to baseline. Throughout this period, AIx was inversely associated with cerebral pulsatility. While the association was weak it suggests that decreases in AIx75 are accompanied by small increases in cerebral pulsatility following GTN. While somewhat speculative, repeated and/or prolonged administration of GTN (or similar endothelium-independent vasodilators) may result in greater decreases in AIx75 and accompany increased transmission of pulsatile flow into the cerebral vasculature, particularly in individuals with aortic stiffening. As such these findings may have implications for stroke and other cerebral vascular disorders associated with cerebral blood flow pulsatility [14,15]. While medications such as GTN have clearly cardioprotective effects, decreases in AIx in individuals with aortic stiffening may expose the cerebral microvasculature to an increased flow pulsatility and influence the incidence of stroke and other cerebral vascular disorders related to cerebral pulsatility.

\subsection{Limitations}

First, the strength of the prediction of the variance in MCAPI from alterations in AIx found here is low. Despite this, these data suggest that to some extent AIx shares an inverse relationship with cerebral pulsatility that is independent of age, gender, height, BMI and other traditional hemodynamic parameters that would be reasonably expected to influence cerebral pulsatility. In addition, the observation regarding an effect of AIx on MCAPI during GTN administration are consistent when investigating the cross-sectional data. To the best of our knowledge, these findings in a healthy population are novel. Second, the measurement of cerebral pulsatility was obtained using transcranial Doppler measures of blood velocity from the MCA. The MCA is responsible for a large majority $(\sim 80 \%)$ of the blood perfusing the cerebral circulation. Given this, changes in pulsatility in this vessel likely influences cerebral health. That said, we are unable to ascertain whether the association between AIx and cerebral pulsatility with and without GTN administration was also evident in other cerebral arteries. This warrants further investigation. 


\section{CONCLUSION}

In a healthy population, the relationship between CPP and cerebral pulsatility is weakly modified by AIx in steady state resting conditions and following acute reductions in AIx75 with GTN.

\section{CONFLICTS OF INTEREST}

The authors declare they have no conflicts of interest.

\section{AUTHORS' CONTRIBUTION}

JP and BMD contributed in study conceptualization. JP, CME, CC, ZJS and BMD contributed in writing (review \& editing) the manuscript. JP, LW, JC, JRC, ZJS and BMD contributed in data curation. $\mathrm{JP}$ and BMD contributed in formal analysis and writing (original draft). BMD, JRC, CME and CC contributed in funding acquisition and project administration.

\section{ACKNOWLEDGMENTS}

We would like to thank the subjects for participating in our study. We would also like to thank Jena Kern, R.N. and Naomi Kennedy, R.N. for their technical assistance. This work was funded, in part, by the National Institute for Health Research (NIHR) Cambridge Biomedical Research Centre. The views expressed are those of the authors and not necessarily those of the NIHR. There are no conflicts of interest to report.

\section{REFERENCES}

[1] Mitchell GF, Parise H, Benjamin EJ, Larson MG, Keyes MJ, Vita JA, et al. Changes in arterial stiffness and wave reflection with advancing age in healthy men and women: the Framingham Heart Study. Hypertension 2004;43:1239-45.

[2] McEniery CM, Yasmin, Hall IR, Qasem A, Wilkinson IB, Cockcroft JR. Normal vascular aging: differential effects on wave reflection and aortic pulse wave velocity: the AngloCardiff Collaborative Trial (ACCT). J Am Coll Cardiol 2005;46:1753-60.

[3] Ben-Shlomo Y, Spears M, Boustred C, May M, Anderson SG, Benjamin EJ, et al. Aortic pulse wave velocity improves cardiovascular event prediction: an individual participant meta-analysis of prospective observational data from 17,635 subjects. J Am Coll Cardiol 2014;63:636-46.

[4] Laurent S, Boutouyrie P, Asmar R, Gautier I, Laloux B, Guize L, et al. Aortic stiffness is an independent predictor of all-cause and cardiovascular mortality in hypertensive patients. Hypertension 2001;37:1236-41.

[5] Laurent S, Katsahian S, Fassot C, Tropeano AI, Gautier I, Laloux $\mathrm{B}$, et al. Aortic stiffness is an independent predictor of fatal stroke in essential hypertension. Stroke 2003;34:1203-6.

[6] O'Rourke MF, Safar ME. Relationship between aortic stiffening and microvascular disease in brain and kidney: cause and logic of therapy. Hypertension 2005;46:200-4.
[7] Gosling RG, Lo PTS, Taylor MG. Interpretation of pulsatility index in feeder arteries to low-impedance vascular beds. Ultrasound Obstet Gynecol 1991;1:175-9.

[8] Reusch P, Wagdy H, Reusch R, Wilson E, Ives HE. Mechanical strain increases smooth muscle and decreases nonmuscle myosin expression in rat vascular smooth muscle cells. Circ Res 1996;79:1046-53.

[9] Witteman JCM, Grobbee DE, Valkenburg HA, van Hemert AM, Stijnen Th, Burger $\mathrm{H}$, et al. J-shaped relation between change in diastolic blood pressure and progression of aortic atherosclerosis. Lancet 1994;343:504-7.

[10] Willum-Hansen T, Staessen JA, Torp-Pedersen C, Rasmussen S, Thijs L, Ibsen H, et al. Prognostic value of aortic pulse wave velocity as index of arterial stiffness in the general population. Circulation 2006;113:664-70.

[11] Sörös P, Whitehead S, Spence JD, Hachinski V. Antihypertensive treatment can prevent stroke and cognitive decline. Nat Rev Neurol 2013;9:174-8.

[12] Henskens LHG, Kroon AA, van Oostenbrugge RJ, Gronenschild EHBM, Fuss-Lejeune MMJJ, Hofman PAM, et al. Increased aortic pulse wave velocity is associated with silent cerebral small-vessel disease in hypertensive patients. Hypertension 2008;52:1120-6.

[13] Salonen R, Salonen JT. Determinants of carotid intima-media thickness: a population-based ultrasonography study in eastern Finnish men. J Intern Med 1991;229:225-31.

[14] Liao D, Cooper L, Cai J, Toole J, Bryan N, Burke G, et al. The prevalence and severity of white matter lesions, their relationship with age, ethnicity, gender, and cardiovascular disease risk factors: the ARIC Study. Neuroepidemiology 1997;16:149-62.

[15] Tsao CW, Seshadri S, Beiser AS, Westwood AJ, Decarli C, Au R, et al. Relations of arterial stiffness and endothelial function to brain aging in the community. Neurology 2013;81:984-91.

[16] Wong TY, Klein R, Sharrett AR, Couper DJ, Klein BEK, Liao DP, et al. Cerebral white matter lesions, retinopathy, and incident clinical stroke. JAMA 2002;288:67-74.

[17] Au R, Massaro JM, Wolf PA, Young ME, Beiser A, Seshadri S, et al. Association of white matter hyperintensity volume with decreased cognitive functioning: the Framingham Heart Study. Arch Neurol 2006;63:246-50.

[18] Kalaria RN, Akinyemi R, Ihara M. Does vascular pathology contribute to Alzheimer changes? J Neurol Sci 2012;322:141-7.

[19] Mitchell GF. Effects of central arterial aging on the structure and function of the peripheral vasculature: implications for endorgan damage. J Appl Physiol (1985) 2008;105:1652-60.

[20] Vlachopoulos C, Aznaouridis K, O’Rourke MF, Safar ME, Baou K, Stefanadis C. Prediction of cardiovascular events and all-cause mortality with central haemodynamics: a systematic review and meta-analysis. Eur Heart J 2010;31:1865-71.

[21] Safar ME, Nilsson PM, Blacher J, Mimran A. Pulse pressure, arterial stiffness, and end-organ damage. Curr Hypertens Rep 2012;14:339-44.

[22] Tarumi T, Ayaz Khan M, Liu J, Tseng BM, Parker R, Riley J, et al. Cerebral hemodynamics in normal aging: central artery stiffness, wave reflection, and pressure pulsatility. J Cereb Blood Flow Metab 2014;34:971-8.

[23] Nakano T, Munakata A, Shimaura N, Asano K, Ohkuma H. Augmentation index is related to white matter lesions. Hypertens Res 2012;35:729-32.

[24] Kim MO, Li Y, Wei F, Wang J, O’Rourke MF, Adji A, et al. Normal cerebral vascular pulsations in humans: changes with 
age and implications for microvascular disease. J Hypertens 2017;35:2245-56.

[25] Feihl F, Liaudet L, Waeber B. The macrocirculation and microcirculation of hypertension. Curr Hypertens Rep 2009;11:182-9.

[26] Fitchett DH, Simkus GJ, Beaudry JP, Marpole DGF. Reflected pressure waves in the ascending aorta: effect of glyceryl trinitrate. Cardiovasc Res 1988;22:494-500.

[27] Yaginuma T, Avolio A, O’Rourke M, Nichols W, Morgan JJ, Roy P, et al. Effect of glyceryl trinitrate on peripheral arteries alters left ventricular hydraulic load in man. Cardiovasc Res 1986;20:153-60.

[28] O'Brien E, Mee F, Atkins N, Thomas M. Evaluation of three devices for self-measurement of blood pressure according to the revised British Hypertension Society Protocol: the Omron HEM705CP, Philips HP5332, and Nissei DS-175. Blood Press Monit 1996;1:55-61.

[29] Pauca AL, O'Rourke MF, Kon ND. Prospective evaluation of a method for estimating ascending aortic pressure from the radial artery pressure waveform. Hypertension 2001;38:932-7.

[30] Wilkinson IB, Fuchs SA, Jansen IM, Spratt JC, Murray GD, Cockcroft JR, et al. Reproducibility of pulse wave velocity and augmentation index measured by pulse wave analysis. J Hypertens 1998;16:2079-84.

[31] Gosling RG, King DH. Arterial assessment by Doppler-shift ultrasound. Proc R Soc Med 1974;67:447-9.

[32] Leenders KL, Perani D, Lammertsma AA, Heather JD, Buckingham P, Healy MJR, et al. Cerebral blood flow, blood volume and oxygen utilization: normal values and effect of age. Brain 1990;113:27-47.

[33] Ainslie PN, Cotter JD, George KP, Lucas S, Murrell C, Shave R, et al. Elevation in cerebral blood flow velocity with aerobic fitness throughout healthy human ageing. J Physiol 2008;586:4005-10.

[34] Wilkinson IB, MacCallum H, Flint L, Cockcroft JR, Newby DE, Webb DJ. The influence of heart rate on augmentation index and central arterial pressure in humans. J Physiol 2000;525: 263-70.

[35] Webb AJS, Simoni M, Mazzucco S, Kuker W, Schulz U, Rothwell PM. Increased cerebral arterial pulsatility in patients with leukoaraiosis: arterial stiffness enhances transmission of aortic pulsatility. Stroke 2012;43:2631-6.

[36] Mitchell GF, van Buchem MA, Sigurdsson S, Gotal JD, Jonsdottir MK, Kjartansson Ó, et al. Arterial stiffness, pressure and flow pulsatility and brain structure and function: the Age, Gene/Environment Susceptibility - Reykjavik study. Brain 2011;134:3398-407.
[37] Xu TY, Staessen JA, Wei FF, Xu J, Li FH, Fan WX, et al. Blood flow pattern in the middle cerebral artery in relation to indices of arterial stiffness in the systemic circulation. Am J Hypertens 2012;25:319-24.

[38] Young VG, Halliday GM, Kril JJ. Neuropathologic correlates of white matter hyperintensities. Neurology 2008;71:804-11.

[39] Boutouyrie P, Bussy C, Lacolley P, Girerd X, Laloux B, Laurent S. Association between local pulse pressure, mean blood pressure, and large-artery remodeling. Circulation 1999;100:1387-93.

[40] Bots ML, Breslau PJ, Briët E, de Bruyn AM, van Vliet HH, van den Ouweland FA, et al. Cardiovascular determinants of carotid artery disease. The Rotterdam Elderly Study. Hypertension 1992;19:717-20.

[41] Bots ML, Hoes AW, Koudstaal PJ, Hofman A, Grobbee DE. Common carotid intima-media thickness and risk of stroke and myocardial infarction: the Rotterdam Study. Circulation 1997;96:1432-7.

[42] Folkow B, Griyby G, Thulesius O. Adaptive structural changes of the vascular walls in hypertension and their relation to the control of the peripheral resistance. Acta Physiol Scand 1958;44:255-72.

[43] Mattace-Raso FUS, van der Cammen TJM, Hofman A, van Popele NM, Bos ML, Schalekamp MADH, et al. Arterial stiffness and risk of coronary heart disease and stroke: the Rotterdam Study. Circulation 2006;113:657-63.

[44] Mitchell GF, Hwang SJ, Vasan RS, Larson MG, Pencina MJ, Hamburg NM, et al. Arterial stiffness and cardiovascular events: the Framingham Heart Study. Circulation 2010;121:505-11.

[45] Sutton-Tyrrell K, Najjar SS, Boudreau RM, Venkitachalam L, Kupelian V, Simonsick EM, et al. Elevated aortic pulse wave velocity, a marker of arterial stiffness, predicts cardiovascular events in well-functioning older adults. Circulation 2005;111:3384-90.

[46] Darne B, Girerd X, Safar M, Cambien F, Guize L. Pulsatile versus steady component of blood pressure: a cross-sectional analysis and a prospective analysis on cardiovascular mortality. Hypertension 1989;13:392-400.

[47] Springo Z, Toth P, Tarantini S, Ashpole NM, Tucsek Z, Sonntag WE, et al. Aging impairs myogenic adaptation to pulsatile pressure in mouse cerebral arteries. J Cereb Blood Flow Metab 2015;35:527-30.

[48] Toth P, Tarantini S, Springo Z, Tucsek Z, Gautam T, Giles CB, et al. Aging exacerbates hypertension-induced cerebral microhemorrhages in mice: role of resveratrol treatment in vasoprotection. Aging Cell 2015;14:400-8. 